\title{
Effects of dipyrone on the digestive tract
}

\author{
E.F. Collares ${ }^{1}$ and L.E.A. Troncon ${ }^{2}$ \\ ${ }^{1}$ Departamento de Pediatria, Faculdade de Ciências Médicas, Universidade Estadual de Campinas, Campinas, SP, Brasil \\ ${ }^{2}$ Departamento de Clinica Médica, Faculdade de Medicina de Ribeirão Preto, Universidade de São Paulo, Ribeirão Preto, SP, \\ Brasil
}

\begin{abstract}
Dipyrone (metamizole), acting through its main metabolites 4-methyl-amino-antipyrine and 4-amino-antipyrine, has established analgesic, antipyretic, and spasmolytic pharmacological effects, which are mediated by poorly known mechanisms. In rats, intravenously administered dipyrone delays gastric emptying (GE) of liquids with the participation of capsaicin-sensitive afferent fibers. This effect seems to be mediated by norepinephrine originating from the sympathetic nervous system but not from the superior celiac-mesenteric ganglion complex, which activates $\beta 2$-adrenoceptors. In rats, in contrast to nonselective nonhormonal anti-inflammatory drugs, dipyrone protects the gastric mucosa attenuating the development of gastric ulcers induced by a number of agents. Clinically, it has been demonstrated that dipyrone is effective in the control of colic-like abdominal pain originating from the biliary and intestinal tracts. Since studies in humans and animals have demonstrated the presence of $\beta_{2}-$ adrenoceptors in biliary tract smooth muscle and $\beta_{2}$-adrenoceptor activation has been shown to occur in dipyrone-induced delayed GE, it is likely that this kind of receptors may participate in the reduction of smooth muscle spasm of the sphincter of Oddi induced by dipyrone. There is no evidence that dipyrone may interfere with small bowel and colon motility, and the clinical results of its therapeutic use in intestinal colic appear to be due to its analgesic effect.
\end{abstract}

Key words: Dipyrone; Gastric emptying; Gastric mucosa; Sphincter of Oddi; Intestinal Motility; Adrenergic receptors

\section{Introduction}

Antipyrine (phenazone), a compound with a relatively simple structure synthesized around 1880 , has been used as an antipyretic and analgesic agent $(1,2)$. This drug is metabolized by mitochondrial enzymes in the liver and generates as a main product 4-hydroxyantipyrine and its conjugates, which are eliminated in the urine (2).

Further modifications of the antipyrine molecule aiming at improving its analgesic and antipyretic properties gave origin to various pharmaceuticals, such as aminophenazone (aminopiryne or amidopyrine), propyphenazone, dipyrone (metamizole), and phenylbutazone (1).

More recently, other pyrazolone derivatives have been synthesized and have experimentally demonstrated effective analgesic, anti-inflammatory, antiplatelet, and anticonvulsant activities, among other effects (3).

Clinically, dipyrone shows powerful analgesic, antipyretic, and antispasmodic effects, whereas its anti-inflammatory activity is considered irrelevant (4).

Dipyrone, as the most popular pyrazolone derivative, is a drug extensively employed therapeutically in some countries, whereas its use has been banned or restricted in others due to its possible undesired and dangerous reactions, such as agranulocytosis (4). Dipyrone is generally regarded as a pro-drug that generates in vivo larger metabolites, such as 4-methyl-amino-antipyrine (MAA), 4-amino-antipyrine (AA), 4-acetyl-amino-antipyrine (AAA), and 4-formyl-amino-antipyrine (FAA) $(1,4)$. Its pharmacological effects are attributed to the active metabolites MAA and $A A(1,4,5)$. In humans and rats, non-enzymatic hydrolysis of dipyrone generates MAA, which is subsequently metabolized in the liver under the action of cytochrome P450 subfamilies $(6,7)$.

In the present text, detailed information is provided regarding the mechanisms of dipyrone pharmacological actions, and the effects on gastrointestinal motility, gastric mucosa, and the spasmolytic property of this drug.

\section{Material and Methods}

For the present review, we analyzed papers available in the PubMed database up to December 2017, using the following key words, separately or in combination: dipyrone (metamizole), mechanisms, gastrointestinal motility, gastric emptying, gastric mucosa, colic pain, sphincter of Oddi, sympathetic nervous system, adrenergic receptors, cyclooxygenases (COXs). Studies in which dipyrone effects were assessed in combination with other drugs (composite preparations) were not included. 


\section{Mechanisms of action}

Although dipyrone is known as a powerful analgesic and antipyretic agent, the identification of the mechanisms involved in these effects lags considerably behind the advances observed regarding other drugs with similar properties.

Recent work has suggested possible mechanisms involved in the triggering of experimental endotoxic (lipopolysaccharide, LPS) fever by the rapid peripheral production of prostaglandin $E_{2}\left(P_{G}\right)$ followed by maintenance of its synthesis (8). This generates a pyrogenic message that reaches the central nervous system (CNS) through mechanisms involving both neuronal pathways (afferent pathway of the vagus nerve) and humoral pathways (8). Evidence obtained in experimental models has shown that the dipyrone MAA metabolite inhibits both $\mathrm{PGE}_{2^{-}}$ dependent and -independent fever, whereas $A A$ blocks $\mathrm{PGE}_{2}$-dependent fever $(9,10)$.

Dipyrone is currently classified as a non-opioid analgesic, although for a long time it was incorrectly included in the group of non-steroidal anti-inflammatory drugs (NSAID) (11). The mechanisms involved in its analgesic effect are not clearly understood and controversial results have been often reported.

Inhibition of cyclooxygenase 3 (COX-3), a variant of COX-1, by analgesic/antipyretic drugs with low anti-inflammatory activity such as dipyrone (including its MAA metabolite) and antipyrine may possibly be the primary CNS mechanism for the reduction of pain (12).

In addition to COX-3 inhibition, both the opioidergic and cannabinoid systems may be involved in the analgesic effect of the drug, or rather of its active metabolites (11). Studies in mice suggest the participation of endogenous cannabinoid and vanilloid systems $(5,13,14)$ with activation of cannabinoid receptor type 1 (CB1) and transient receptor potential vanilloid 1 (TRPV1) receptors, respectively, in the periaqueductal-gray rostral ventromedial medulla axis of the CNS (14). In this animal model, parenterally administered dipyrone and antipyrine, but not MAA, blocked the transient receptor potential ankyrin 1 (TRPA1) channel. This receptor is expressed by peripheral sensory neurons with cell bodies in the dorsal root ganglia, functioning as antagonists of this channel, which, when activated, have a hyperalgesic nociceptive effect (15). On the other hand, another study concluded that arachidonoyl metabolites, which depend on the action of the fatty acid amide hydrolase, and cannabinoid receptors do not participate in the pharmacological effects of this drug under non-inflammatory conditions (16). In addition, a study also conducted in mice suggested that, in acute pain tests, cannabinoid CB1 receptors do not participate in the antinociceptive effect of dipyrone administered intraperitoneally, although the participation of these receptors in other pain models (neuropathy, inflammation, etc.) or in different routes of administration of the drug was not ruled out (17).
The involvement of the descending spinal pathways in the analgesic effect of dipyrone is controversial. One study concluded that the descending spinal adrenergic ( $\alpha_{2}$-adrenoceptors) and serotonergic (5-HT receptors) pathways do not participate in this effect (18). More recently, however, evidence has been reported that various subtypes of serotonergic receptors $\left(5-\mathrm{HT}_{2 \mathrm{a}}, 5-\mathrm{HT}_{3}\right.$, and 5 - $\mathrm{HT}_{7}$-serotonergic) and adrenergic subtypes $\left(\alpha_{1}, \alpha_{2}, \beta\right.$ adrenergic receptors) mediate the antinociceptive effect of dipyrone (19).

The central analgesic effect of this drug has been contested in a rat model of inflammatory pain (intraplantar injection of $\lambda$-carrageenan), thus suggesting that its peripheral action is not opioid-dependent (20).

It has been found in rats that thirty minutes after local administration of dipyrone the anti-hyperalgesic effect is associated to the activation of neuronal CB1 receptors induced by the AA metabolite and MAA-induced cGMP activation, with opening of the neuronal $\mathrm{K}_{\text {ATP }}$ channel (21). In contrast, another study also conducted in rats concluded that cannabinoid receptors are not involved in the peripheral antinociception induced by dipyrone (22). However, in the latter study the antinociceptive effect was evaluated 5 min after local (paw) administration of dipyrone and $15 \mathrm{~min}$ after local application of the CB1 and CB2 cannabinoid receptor antagonists in a model of hyperalgesia with previous local application of $\mathrm{PGE}_{2}$. Because of the need to generate active metabolites at the site of dipyrone application (23), the short time between application and evaluation of the effect in this study raises the possibility that the required local concentrations of these metabolites were not reached, thus making debatable the interpretation of this study and of others that used the same model.

\section{Effects on the stomach}

\section{Gastric motor activity}

More than 30 years ago it was observed that antipyrine per os (po) $(100 \mathrm{mg} / \mathrm{kg})$ and intravenous (iv) dipyrone $(50,250$, and $1250 \mathrm{mg} / \mathrm{kg})$ delay gastric emptying (GE) in rats $(24,25)$.

Using saline as the test meal, this phenomenon was confirmed after iv administration of equimolar doses (240 $\mu \mathrm{mol} / \mathrm{kg}$ ) of dipyrone $(80 \mathrm{mg} / \mathrm{kg}$ ) and antipyrine $(45.17 \mathrm{mg} /$ $\mathrm{kg}$ ), and was amplified with the inclusion of the AA metabolite $(48.77 \mathrm{mg} / \mathrm{kg})(26-29)$. Additional experiments conducted in an attempt to identify the mechanisms involved have shown that: 1) the iv effect of the three drugs was dose dependent (26-29); 2) at the dose of $240 \mu \mathrm{mol} / \mathrm{kg}$ a maximum effect occurred 10 min after antipyrine administration and during the first hour after the administration of dipyrone and AA (26-29); 3) dipyrone was the only drug that caused delayed GE when applied by the intracerebroventricular (icv) route (26-29); 4) electrolytic lesion of the paraventricular nucleus (PVN) of the hypothalamus abolished the iv effect of dipyrone (26); 5) subdiaphragmatic 
vagotomy significantly reduced the effect of the three drugs (26-29); 6) dipyrone and antipyrine administered by the parenteral route increased gastric compliance $(28) ; 7$ ) icv administration of baclofen, a $\mathrm{GABA}_{\mathrm{B}}$ receptor agonist, blocked the parenteral effect of dipyrone, $A A$, and antipyrine, and of dipyrone administered icv (27-29); 8) apparently, there is no involvement of nitric oxide in the iv effect of dipyrone, opioids, or dopamine receptors (30).

Treatment of rats with capsaicin during the neonatal period (31), a procedure that causes the degeneration of non-myelinated peripheral afferent neurons $(32,33)$, results in full blockade of the effect of the three drugs (dipyrone, $\mathrm{AA}$, and antipyrine) on GE when administered iv, but not of the effect of icv dipyrone. This finding suggests that neurotoxin-sensitive afferent fibers carry the peripheral stimulus involved in GE delay. In addition, it was reported that the selective blockade of $\mathrm{CCK}_{1}$ or $5-\mathrm{HT}_{3}$ receptors contained in these fibers, which, when activated during the digestive phase delays GE, did not modify the effect of the pyrazolone derivatives (31).

Capsaicin-sensitive afferent fibers of the common hepatic branch of the vagus project towards the rat liver (34). Since dipyrone metabolites are processed by cytochrome P450 in the rat liver (7), the effect of this drug may hypothetically stimulate these fibers through unknown mechanisms. However, results obtained with the parenteral administration of dipyrone, $\mathrm{AA}$, and antipyrine to rats previously submitted to section of the hepatic branch of the vagus indicated that the fibers that pass through this branch are not involved in the mechanisms resulting in delayed GE (35).

Under non-physiological experimental conditions, there is evidence that the adrenergic system is involved in delayed GE in rats (36-40). The possibility of the participation of this system in the effect of these pyrazolone derivatives on GE was investigated and it was found that acute iv adrenergic blockade with guanitidine or iv pretreatment with propranolol (a non-selective $\beta$-adrenergic antagonist) abolished the effect of dipyrone and antipyrine on GE (41). The same procedure significantly reduced, but did not abolish, the effect of the AA metabolite. Propranolol administered icv did not alter the parenteral effect of the three drugs. These results suggest the participation of the adrenergic system in the delayed GE phenomenon by activation of $\beta_{1}$-and/or $\beta_{2}$-adrenergic receptors through the sympathetic nervous system (SNS).

Bilateral ablation of the adrenal glands, but not of the gland medulla, enhances the emptying of a liquid saline meal in rats (42). Although evidence of the participation of the SNS in the effect of the three drugs was significant, the possibility that part of the neurotransmitter might originate from the medulla of the adrenal glands could not be ruled out. However, bilateral enucleation of the adrenal medulla did not modify significantly the effect of the drugs on GE (Vinagre AM, Collares EF, unpublished results), thus supporting the hypothesis that the neurotransmitter may originate from the peripheral endings of the SNS. $\beta_{1}$ - and $\beta_{2}$-adrenergic receptors have been identified in the gastric mucosa and antrum muscle in rats (43), together with elevated levels of $\beta_{3}$-adrenoceptor mRNA expression in the muscle fibers of the gastric fundus and the pylorus (44). A recent study using previous parenteral administration of selective $\beta_{1^{-}}, \beta_{2^{-}}$, or $\beta_{3}$-adrenergic antagonists suggested that $\beta_{2}$-adrenoceptor activation occurs in the GE delay induced by pyrazolone derivatives (45), while the $\beta_{2}$-adrenergic antagonist butoxamine completely blocked the effect of dipyrone and antipyrine on GE. In addition, this antagonist significantly reduced, but did not abolish, the effect of the AA metabolite, as observed in the previous study (41) using blockade with guanidine or pretreatment with propranolol. These results indicate that: 1) part of the effect of dipyrone on GE is likely to be due to activation of the $\beta_{2}$-adrenoceptor by the AA metabolite; 2) a substantial component of the mechanism involved in the effect of AA (at a dose of $240 \mu \mathrm{mol} / \mathrm{kg}$ ) is unknown.

The same study (45) also ruled out the involvement of the superior celiac-mesenteric ganglion complex of the SNS, so that the peripheral origin of the adrenergic neurotransmitter continues to be unknown. Based on available information, at least three possibilities may be suggested for the neurotransmitter origin: the splanchnic ganglia of the prevertebral ganglion chain, the sympathetic paravertebral ganglion chain for the distal part of the thorax, or the noradrenergic efferent fibers of the vagus nerve (45-49).

\section{Gastric mucosa}

Amongst the well-known complications of the therapeutic use of NSAID, especially the non-selective COX inhibitors, are the development of gastric mucosal ulcers and changes in gastric motility (50). Considering indomethacin (a non-selective COX inhibitor) as the main model of injury to the gastric mucosa induced by NSAID in animals, a recent review on pathogenesis (50) reached the following conclusions: 1) concomitant inhibition of COX-1 (a constitutive isoenzyme) and COX-2 (an induced isoenzyme) is needed for the development of gastric mucosa injuries; 2) COX-1 inhibition and the consequent $\mathrm{PGE}_{2}$ deficiency may be responsible for gastric hypermotility which, in turn, causes vascular injury, microcirculation disorders and reduced mucosal blood flow. Gastric hypermotility may play a primary role in the development of gastric injury, occurring before later phenomena also involved in injury, such as increased neutrophil migration; 3) prostaglandins (PGs) produced by COX-2 induction counterbalance the deleterious effect of COX-1 inhibition alone; 4) the mechanism through which COX-1 inhibition alone induces COX-2 expression is unknown.

Contrary to the participation of gastric hypermotility in mucosal injury is the observation that non-selective COX inhibition by intragastric indomethacin delayed liquid GE in an animal model and reduced gastric tonus (51). This precedes the development of mucosal lesions and neutrophil infiltration, thus suggesting that there is no 
relationship between abnormal gastric motility and mucosal injury (51). Differences regarding stomach motor activity may be possibly due to the route of indomethacin administration, with the subcutaneous route having a parenteral effect (50) and the intragastric route having a local effect (51). One study favoring this interpretation showed that selective iv inhibition of COX-2 by valdecoxib increased gastric tonus in rats (52), suggesting that the abnormal gastric motility detected when indomethacin was administered by the parenteral route (50) may have been due to a predominant inhibition of COX-2.

Dipyrone, in contrast to the non-selective NSAIDs of the COXs, has a distinct effect on the gastric mucosa in humans and animals. Prolonged po treatment (14 days) of rats with dipyrone $\left(60 \mathrm{mg} \cdot \mathrm{kg}^{-1} \cdot 12 \mathrm{~h}^{-1}\right)$ did not cause gastric ulcers, did not affect COX-1 expression, and did not induce COX-2 expression in the gastric mucosa (53). Orogastric administration of higher doses $(1000 \mathrm{mg} / \mathrm{kg})$ induced only few injuries to the gastric mucosa, which does not seem to relate to the significant reduction of $\mathrm{PGE}_{2}$ production, but is associated to inhibition of the NO/cGMP pathway and cNOS activity, which are known as important mucosal protective factors (54). In vitro, in contrast to the classical COX inhibitors, dipyrone and its MAA and AA metabolites apparently inhibit COX activity by either sequestering the radicals that initiate this enzyme catalytic activity or reducing the COX protein oxidative state. This indicates a distinct mechanism of action that may explain the weak antiinflammatory effect of the drug (55).

Acute intraperitoneal (ip) pretreatment of rats with a single dose of dipyrone $(5,25$, and $100 \mathrm{mg} / \mathrm{kg}$ ) attenuated the development of ulcers induced by histamine and diethyldithiocarbamate, but not of those induced by stress. In control animals with no gastric ulcer, $5 \mathrm{mg} / \mathrm{kg}$ ip dipyrone increased $\mathrm{PGE}_{2}$ in the gastric contents (56). The protective effect of dipyrone was considered to be due to the increased synthesis and/or release of gastric mucus and to the increased gastric content of $\mathrm{PGE}_{2}$ (56). In addition, 3-day ip pretreatment with dipyrone $(25,50$, and $100 \mathrm{mg} / \mathrm{kg})$ reduced both the ulcer index and mucus secretion in rats with gastric ulcer induced by stress and diethyldithiocarbamate (57).

A significant increase in the risk of upper digestive bleeding induced by dipyrone, although twice lower than that of aspirin, has been identified in adult humans (58). Dipyrone administered po to healthy volunteers for two weeks ( $1.5 \mathrm{~g} /$ day) had no effect on the gastric or duodenal mucosa, with discrete damage being observed only with a higher dose (3 g/day) (59).

From another viewpoint, it is well known that, in humans, gastric-secreted acid and pepsin comprise an important factor in the genesis, maintenance, or worsening of the upper digestive tract mucosal injury, such as those found in erosive esophagitis due to gastroesophageal reflux, gastric and, especially, duodenal peptic ulcers and NSAID-induced lesions (60). No information, however, was found in the literature regarding the effect of dipyrone on the production of these two components of gastric secretion. Nevertheless, it is possible to speculate that absence of gastric ulcers associated to the use of dipyrone may be due to the interference of the drug in the regulation of gastric secretion. Thus, using an in vivo model for the study of gastric secretion in rats with iv administration of several drugs, isoprenaline (isoproterenol), a $\beta_{1}$ - $\beta_{2}$-adrenergic agonist, inhibited the acid secretion induced by pentagastrin, an effect that was abolished by the administration of propranolol or butoxamine (61). In contrast, an in vitro study with an isolated stomach preparation showed that propranolol inhibited the enhancement of acid secretion induced by isoprenaline, a phenomenon that was not affected by butoxamine (61). These results lead to the conclusion that isoprenaline has an indirect (parenteral) inhibitory effect and a direct stimulatory effect on gastric acid secretion in rats, both involving activation of $\beta$-adrenoceptors (61). Since $\beta$-adrenoceptor activation by the parenteral route inhibits gastric acid secretion, it may be concluded indirectly that dipyrone, by activating these receptors in the stomach via the SNS, may have a protective effect on the gastric mucosa. However, findings from other studies did not support this interpretation. In three models of ulceration induced by ethanol, indomethacin, and stress in awake rats, po or ip pretreatment with propranolol (62) and butoxamine (63) prevented injury to the gastric mucosa, an effect attributed to reinforcement of the mucosal barrier by $\beta$-adrenergic antagonists due to the preservation of mucusproducing cells and of mucosal integrity. In anesthetized rats, using the same models on an ex-vivo gastric chamber preparation, butoxamine administered intragastrically or ip did not change the production of pepsin or acid, indicating that the antiulcerogenic action of this $\beta_{2}$-adrenergic antagonist was not related to a reduced secretion of these components (63).

In conclusion, the mechanisms by which dipyrone, in contrast to nonselective NSAIDs, has a protective effect on the gastric mucosa are still unclear.

\section{Effect on intestinal motility}

Studies using in vitro preparations of smooth muscle have reported controversial results regarding the spasmolytic activity of dipyrone (64-68). These conflicting results may be related to the fact that dipyrone is a pro-drug that may not have a direct effect on the muscle in vitro but acts indirectly through its metabolites, MAA in particular, which is generated by the drug hydrolysis (23). Ergün et al. (69) defined the following factors as being important for the in vitro effects of dipyrone: occurrence of non-enzymatic drug hydrolysis, local drug concentrations, and conditions related to $\mathrm{pH}$, temperature and period of incubation of the muscle preparation in the organ bath. All these conditions must be strictly controlled in order to obtain reliable results. 
Little information is available about the action of dipyrone on intestinal motility. Small bowel peristalsis of guinea pig intestine is not blocked when exposed in vitro to 10-100 $\mu \mathrm{M}$ dipyrone in a bath for $60 \mathrm{~min}(70)$. In contrast, at higher concentrations $(100-500 \mu \mathrm{M})$, the drug had a myogenic spasmolytic effect for $30 \mathrm{~min}$ in the ileum (71). On the other hand, dipyrone (50 and $250 \mathrm{mg} / \mathrm{kg}$ ) administered in vivo to rats did not change the intestinal transit (25), and the drug had no effect on experimentally induced contractions of the cecum of ponies (72), and on the jejunal or colonic (pelvic flexure) motility of these animals (73). In the awake opossum, without the addition of any other active principle, the drug was not able to break the migrating motor complex (MMC) cycle (74).

Whether the drug has or not a spasmolytic action on intestinal colic is inconclusive, since experimental studies on animals have suggested that the positive clinical results observed in humans and animals may be due to its analgesic property.

\section{Effect on the biliary tract}

Sphincter of Oddi dysfunction may manifest clinically by recurrent abdominal pain of the "biliary type" and/or episodes of acute pancreatitis, with abnormal motility of the sphincter and a significant increase in its basal pressure having been identified (75). In this condition, dipyrone was proven more effective in controlling acute biliary colic pain than opioids or pure spasmolytic drugs (76). However, a systematic review and meta-analysis found that NSAIDs were more effective in both control of biliary colic and prevention of potential progression to cholelithiasis than opioids, spasmolytic drugs, or dipyrone, probably because of the diversity of their pharmacological actions, locally and in the CNS (77). A more recent meta-analysis that did not include dipyrone also indicated that NSAIDs were superior to placebo and spasmolytic drugs, but not to opioids, in the control of biliary colic, additionally indicating a reduction in the frequency of complications related to the biliary tract (78).

Dipyrone was found to reduce the tonus of the sphincter of Oddi in humans, which possibly indicates another mechanism of action on biliary colic, in addition to the analgesic effect (79). Conversely, dipyrone did not change the biliary pressure or the sphincter of Oddi myoelectric activity in the non-sedated opossum (74). No information was found in the literature about the effect of the drug on the biliary pathways in rats.

The sphincter of Oddi in species such as the opossum, the guinea pig, and the rabbit has different anatomical and functional motor characteristics than those of humans (80). This is not the case for carnivore animals (dogs and cats), in which the structure and function of the sphincter of Oddi were found to be similar to those of humans $(80,81)$.

In dogs and cats, the sphincter of Oddi is under direct adrenergic control from the sympathetic plexus and ganglia, with the participation of adrenergic axons of the vagus being apparently questionable (82). In addition, sympathetic stimulation causes relaxation of the gallbladder through a direct effect, which was found in dogs and cats and in humans as well (83).

Adrenergic fibers were found to partially mediate relaxation of the isolated gallbladder of dogs, with a significant component of this effect depending on non-cholinergic, non-adrenergic neurotransmitters (nitric oxide, intestinal vasoactive peptide, and carbon monoxide) (84).

In an isolated preparation of the sphincter of Oddi of cats, it was demonstrated that $\alpha$-adrenoceptor activation promotes contraction, whereas activation of $\beta$-adrenoceptors promotes relaxation (85). In anesthetized cats, the sphincter of Oddi tonus increased in vivo due to the activation of $\alpha$-adrenoceptors and decreased with the activation of $\beta$-adrenoceptors probably with the involvement of the $\beta_{2}$-adrenergic subtype (86). In addition, in anesthetized cats, the activation of the $\beta_{2}$-adrenoceptor induced relaxation of the sphincter of Oddi, a phenomenon antagonized by propranolol and by the selective blockade of the $\beta_{2}$-adrenergic receptor (87).

Although the use of results from experiments in animals to interpret what occurs in humans is limited, a reasonable amount of information allows the speculation that the activation of $\beta_{2}$-adrenoceptors by metabolites of dipyrone (the same involved in delaying GE in rats) may contribute, at least in part, to the drug spasmolytic effect on biliary colic. In this clinical situation, this effect may occur in addition to the analgesic property of the drug. However, the demonstration of the participation of the $\beta_{2}$-adrenergic subtype in the effect of dipyrone in humans may be questioned, taking into account that the selective adrenergic antagonists currently available also block $\beta$-adrenoceptors in the respiratory apparatus, provoking bronchospasm (88).

\section{Relationship between the antinociceptive and antispasmodic effects of dipyrone}

A few studies have examined the antinociceptive effect of dipyrone in rats $(20,21)$. Hernández-Delgadillo et al. (89) and Silva-Moreno et al. (90) evaluated this effect using extremely high doses of iv dipyrone, i.e., 7.5 and 5 times higher, respectively, than those employed in studies of the effect of the drug on GE of liquids in rats $(26-31,35,41,45)$. Rupp et al. (25), in a study of the effect of dipyrone on GE in rats, used $1250 \mathrm{mg} / \mathrm{kg}$ iv as the maximum dose. However, the authors detected a significant delay of GE with a lower dose $(50 \mathrm{mg} / \mathrm{kg}$ ). In our first observation (26), the delay of GE was already significant with a dose of $40 \mathrm{mg} / \mathrm{kg}$. In subsequent studies, the dose of $80 \mathrm{mg} / \mathrm{kg}$ was used as reference. The relationships between the effects of dipyrone on GE of rats and its antinociceptive influence is therefore unknown, and whether this is dependent on dosage is uncertain. On the basis of the dose-response curves of the two mentioned studies $(89,90)$, we observed that the dose 
of $80 \mathrm{mg} / \mathrm{kg}$ is lower than the lower limit of the curve of the antinociceptive effect (percent of maximum possible effect) of this drug in rats. Although this is a rough interpretation, it may indicate that there is no relationship between the two effects.

\section{Unknown effects on the digestive tract}

We did not find information in the literature available on the effect of dipyrone on the motor activity of the stomach in humans. In addition, there is no information on the effect of the drug on the motor activity of other parts of the gastrointestinal tract, such as the esophagus and the lower esophageal sphincter, the pylorus, or the internal anal sphincter, both in humans or animals.

\section{Research proposals}

The available information regarding the effect of pyrazolone derivatives on GE in rats is limited, which indicates

\section{References}

1. Brogden RN. Pyrazolone derivatives. Drugs 1986; 32: 60-70, doi: 10.2165/00003495-198600324-00006.

2. Stevenson $\mathrm{IH}$. Factors influencing antipyrine elimination. Br J Clin Pharmacol 1977; 4: 261-265, doi: 10.1111/j.1365-2125. 1977.tb00710.x.

3. Küçükgüzel SG, Senkardes S. Recent advances in bioactive pyrazoles. Eur J Med Chem 2015; 97: 786-815, doi: 10. 1016/j.ejmech.2014.11.059.

4. Levy M, Zylber-Katz E, Rosenkranz B. Clinical pharmacokinetics of dipyrone and its metabolites. Clin Pharmacokinet 1995; 28: 216-234, doi: 10.2165/00003088-199528030-00 004.

5. Rogosch T, Sinning C, Podlewski A, Watzer B, Schlosburg $\mathrm{J}$, Lichtman $\mathrm{AH}$ et al. Novel bioactive metabolites of dipyrone (metamizol). Bioorg Med Chem 2012; 20: 101107, doi: 10.1016/j.bmc.2011.11.028.

6. Geisslinger G, Böcker R, Levy M. High-performance liquid chromatographic analysis of dipyrone metabolites to study their formation in human liver microsomes. Pharm Res 1996; 13: 1272-1275, doi: 10.1023/A:1016088925786.

7. Kraul H, Pasanen $M$, Sigusch $H$, Stenbäck $F$, Park SS, Gelboin HV, et al. Immunohistochemical properties of dipyrone-induced cytochromes P450 in rats. Hum Exp Toxicol 1996; 15: 45-50, doi: 10.1177/096032719601500108.

8. Roth J, Blatteis CM. Mechanisms of fever production and Iysis: Lessons from experimental LPS fever. Compr Physiol 2014; 4: 1563-1604, doi: 10.1002/cphy.c130033.

9. Malvar Ddo C, Soares DM, Fabrício ASC, Kanashiro A, Machado RR, Figueiredo MJ, et al. The antipyretic effect of dipyrone is unrelated to inhibition of PGE2 synthesis in the hypothalamus. Br J Pharmacol 2011; 162: 1401-1409, doi: 10.1111/j.1476-5381.2010.01150.x.

10. Malvar Ddo C, Aguiar FA, Vaz Ade LL, Assis DCR, de Melo MCC, Jabor VAP, et al. Dipyrone metabolite 4-MAA induces the need of further studies in order to clarify several points that might help understand the spasmolytic effect of dipyrone on the digestive tract. Among them, the following points should be clarified: 1) degree of participation of the MAA and AA metabolites and others in the effect of dipyrone; 2) mechanism(s) by which pyrazolone derivatives activate the capsaicin-sensitive afferent pathways; 3) mechanism(s) additional to the activation of the $\beta 2$ adrenoceptor mediating the effect of the AA metabolite delaying GE; 4) origin of the norepinephrine mediator in the SNS; 5) participation of the PVN in the integration between the spinal and/or vagal afferent pathways; 6 ) the efferent pathways of the vagus (adrenergic) and the SNS involved in the various effects of dipyrone.

\section{Acknowledgments}

The research was supported by Fundo de Apoio ao Ensino, à Pesquisa e Extensão (FAEPEX), Universidade Estadual de Campinas (UNICAMP), Campinas, SP, Brasil.

hypothermia and inhibits PGE2-dependent and -independent fever while 4-AA only blocks PGE2 -dependent fever. $\mathrm{Br} J$ Pharmacol 2014; 171: 3666-3679, doi: 10.1111/bph.12717.

11. Jasiecka A, Maslanka T, Jaroszewski JJ. Pharmacological characteristics of metamisole. Pol J Vet Sci 2014; 17: 207214, doi: 10.2478/pjvs-2014-0030.

12. Chandrasekharan NV, Dai H, Roos KLT, Evanson NK, Tomsik J, Elton TS, et al. COX-3, a cyclooxygenase-1 variant inhibited by acetaminophen and other analgesic/ antipyretic drugs: Cloning, structure, and expression. Proc Natl Acad Sci 2002; 99: 13926-13931, doi: 10.1073/pnas. 162468699.

13. Crunfli F, Vilela FC, Giusti-Paiva A. Cannabinoid CB1 receptors mediate the effects of dipyrone. Clin Exp Pharmacol Physiol 2015; 42: 246-255, doi: 10.1111/1440-1681.12347.

14. Maione S, Radanova L, De Gregorio D, Luongo L, De Petrocellis L, Di Marzo V, et al. Effects of metabolites of the analgesic agent dipyrone (metamizol) on rostral ventromedial medulla cell activity in mice. Eur J Pharmacol 2015; 748: 115-122, doi: 10.1016/j.ejphar.2014.12.022.

15. Nassini R, Fusi C, Materazzi S, Coppi E, Tuccinardi T, Marone IM, et al. The TRPA1 channel mediates the analgesic action of dipyrone and pyrazolone derivatives. $\mathrm{Br} \mathrm{J}$ Pharmacol 2015; 172: 3397-3411, doi: 10.1111/bph.13129.

16. Schlosburg JE, Radanova L, Di Marzo V, Imming P, Lichtman $\mathrm{AH}$. Evaluation of the endogenous cannabinoid system in mediating the behavioral effect of dipyrone (metamizol) in mice. Behav Pharmacol 2012; 23: 722-726, doi: 10.1097/FBP.0b013e3283584794.

17. Elmas P, Ulugol A. Involvement of cannabinoid CB1 receptors in the antinociceptive effect of dipyrone. $J$ Neural Transm 2013: 120: 1533-1538.

18. Godoy MC, Fighera MR, Souza FR, Flores AE, Rubin MA, Oliveira MR, et al. $\alpha 2$ - Adrenoceptors and 5-HT receptors 
mediate the antinociceptive effect of new pyrazolines, but not dipyrone. Eur J Pharmacol 2004; 496: 93-97, doi: 10.1016/j.ejphar.2004.05.045.

19. Gencer A, Gunduz O, Ulugol A. Involviment of descending serotonergic and noradrenergic systems and their spinal receptor subtypes in the antinoceciptive effect of dipyrone. Drug Res 2015; 65: 645-649, doi: 10.1055/s-0034-1398550.

20. Rezende RM, França DS, Menezes GB, dos Reis WG, Bakhle YS, Francischi JN. Different mechanisms underlie the analgesic actions of paracetamol and dipyrone in rat model of inflammatory pain. Brit $J$ Pharmacol 2008; 153: 760-768, doi: 10.1038/sj.bjp.0707630.

21. Dos Santos GG, Dias EV, Teixeira JM, Athie MCP, Bonet IJ, Tambeli $\mathrm{CH}$, et al. The analgesic effect of dipyrone in peripheral tissue involves two different mechanisms: Neuronal $\mathrm{K}_{\mathrm{ATP}}$ channel opening and $\mathrm{CB}_{1}$ receptor activation. Eur J Pharmacol 2014; 741: 124-131, doi: 10.1016/j.ejphar. 2014.07.019.

22. Silva LCR, Romero TRL, Guzzo LS, Duarte IDG. Participation of cannabinoid receptors in peripheral nociception induced by some NSAIDs. Braz J Med Biol Res 2012; 45: 1240-1243, doi: 10.1590/S0100-879X2012007500153.

23. Ergün H. Pro-drugs in in vitro experiments. Anesth Analg 2005; 101: 606, doi: 10.1213/01.ANE.0000159022.67533.82.

24. Takanaka A, Onoda K, Kainuma E, Lienard F, Omori Y. Effect of phenylpyrazolone derivatives on gastric emptying rate and drug absorption in rats. Jpn J Pharmacol 1973; 23: 745-747, doi: 10.1254/jjp.23.745.

25. Rupp VS, Schroth HJ, Hildebrandt U, Garth H, Feifel G. [The effect of metamizole on gastric emptying and small intestine propulsion in the rat]. Arzneimittelforschung 1987; 37: 1051-1053.

26. Collares EF, Vinagre AM. Evidence of the effect of dipyrone on the central nervous system as a determinant of delayed gastric emptying observed in rats after its administration. Braz J Med Biol Res 2003; 36: 1375-1382, doi: 10.1590/ S0100-879X2003001000014.

27. Soares $A C F$, Vinagre $A M$, Collares EF. Effect of antipyrine on the gastric emptying of liquid in rats. Braz J Med Biol Res 2006; 39: 1507-1512, doi: 10.1590/S0100-879X2006001100015.

28. Vinagre $A M$, Collares EF. Effect of 4-aminoantipyrine on gastric compliance and liquid emptying in rats. Braz $\mathrm{J}$ Med Biol Res 2007; 40: 903-909, doi: 10.1590/S0100-879X200 6005000119.

29. Collares EF, Vinagre AM. Effect of the $G A B A_{B}$ agonist baclofen on dipyrone-induced delayed gastric emptying in rats. Braz J Med Biol Res 2005; 38: 99-104, doi: 10.1590/ S0100-879X2005000100015.

30. Collares EF, Vinagre AM. [Effect of pretreatment with naloxane (antagonist of opioid receptors), L-NAME (NO synthase inhibitor) and metaclopramide (antagonist of dopamine receptors) on delayed gastric emptying in rats induced by dipyrone]. XXII Annual Meeting of the Federação de Sociedades de Biologia Experimental. August 22-25; Águas de Lindóia, SP, Brazil. 2007. p 40.001 (Abstract).

31. Vinagre AM, Collares EF. Phenylpyrazolone derivatives inhibit gastric emptying in rats by a capsaicin-sensitive afferent pathway. Braz J Med Biol Res 2009; 42: 10861089, doi: 10.1590/S0100-879X2009001100014.

32. Gamse R, Leeman SE, Holzer P, Lembeck F. Differential effects of capsaicin on the content of somatostatin, substance
$\mathrm{P}$, and neurotensin in nervous system of the rat. Naunyn Schmiedebergs Arch Pharmacol 1981; 317: 140-148, doi: 10.1007/BF00500070.

33. Jancsó G, Király E. Sensory neurotoxins: Chemically induced selective destruction of primary sensory neurons. Brain Res 1981; 210: 83-89, doi: 10.1016/0006-8993(81)90886-6.

34. Warne JP, Foster MT, Horneman HF, Pecoraro NC, Ginsberg AB, Akana SF, et al. Afferent signalling through the common hepatic branch of the vagus inhibits voluntary lard intake and modifies plasma metabolite levels in rats. J Physiol 2007; 583: 455-467, doi: 10.1113/jphysiol.2007. 135996.

35. Vinagre AM, Collares EF. [Effect of dipyrone, antipyrine and 4-aminoantipyrine on the gastric emptying of young adult rats submitted to section of the hepatic branch of vagus nerve]. XXI Annual Meeting of the Federação de Sociedades de Biologia Experimental, Águas de Lindóia, SP, Brazil, August 23-26, 2006, p. 40.010. (Abstract).

36. Gondim FA, Rodrigues CL, da Graça JR, Camurça FD, de Alencar HMP, dos Santos AA, et al. Neural mechanisms involved in the delay gastric emptying and gastrointestinal transit of liquid after thoracic spinal cord transaction in awake rats. Auton Neurosci 2001; 87: 52-58, doi: 10.1016/ S1566-0702(00)00261-7.

37. Gupta YK, Chaudhary G. Effect of antiemetic drugs on decrease in gastric emptying in experimental model in motion sickness in rats. Acta Pharmacol Sin 2003; 24: 296-300.

38. Tsukada F, Nagura Y, Abe S, Sato N, Ohkubo Y. Effect of restraint and footshock stress and norepinephrine treatment on gastric emptying in rat. Biol Pharm Bull 2003; 26: 368370, doi: $10.1248 / \mathrm{bpb} .26 .368$.

39. Fülöp K, Zádori Z, Rónai AZ, Gyires K. Characterisation of $\alpha_{2-}$ adrenoceptor subtypes involved in gastric emptying, gastric motility and gastric mucosal defense. Eur J Pharmacol 2005; 528: 150-157, doi: 10.1016/j.ejphar.2005.10.025.

40. Nakade $\mathrm{Y}$, Tsuchida D, Fukuda H, Iwa M, Pappas TN, Takahashi T. Restraint stress delays solid gastric emptying via a central CRF and peripheral sympathetic neuron in rats. Am J Physiol Regul Integr Comp Physiol 2005; 288: R427R432, doi: 10.1152/ajpregu.00499.2004.

41. Vinagre AM, Collares EF. Evidence of the involvement of peripheral $\beta$-adrenoceptors in delayed liquid gastric emptying induced by dipyrone, 4-aminoantipyrine and antipyrine in rats. Braz J Med Biol Res 2013; 46: 735-738, doi: 10.1590/ 1414-431X20132975.

42. Ronsini ML, Collares EF. Effects of adrenalectomy and adrenal enucleation on liquid gastric emptying in rats. Braz $J$ Med Biol Res 2000; 33: 1047-1051, doi: 10.1590/S0100879X2000000900009.

43. Yu $O$, Ouyang A. Distribution of $\beta$-adrenoceptor subtypes in gastrointestinal tract of nondiabetic and diabetic BB rats. Dig Dis Sci 1997; 42: 1146-1153, doi: 10.1023/A:10188773 18101.

44. Evans BA, Papaioannou M, Bonazzi VR, Summers RJ. Expression of $\beta_{3}$-adrenoceptor mRNA in rat tissues. Brit $J$ Pharmacol 1996; 117: 210-216, doi: 10.1111/j.1476-5381. 1996.tb15176.x.

45. Vinagre AM, Collares EF. Effect of selective $\beta$-adrenoceptor blockade and surgical resection of the celiac-superior mesenteric ganglion complex on delayed liquid gastric emptying induced by dipyrone, 4-aminoantipyrine and antipyrine in rats. 
Braz J Med Biol Res 2016; 49: e5011, doi: 10.1590/1414$431 \times 20155011$

46. Willing $A E$, Berthoud HR. Gastric distension-induced c-fos expression in catecholaminergic neurons of rat dorsal vagal complex. Am J Physiol 1997; 272: R59-R67, doi: 10.1152/ ajpcell.1997.272.1.C59.

47. Yang M, Zhao X, Miselis RR. The origin catecholaminergic nerve fibers in the subdiaphragmatic vagus nerve of rat. J Auton Nerv Syst 1999; 76: 108-117, doi: 10.1016/S01651838(99)00014-4.

48. Guo JJ, Browning KN, Rogers RC, Travagli RA. Catecholaminergic neurons in rat dorsal nucleus of vagus project selectively to gastric corpus. Am J Physiol Gastrointest Liver Physiol 2001; 280: G361-G367, doi: 10.1152/ajpgi.2001. 280.3.G361.

49. Quinson N, Robbins HL, Clark MJ, Furness JB. Locations and innervations of cell bodies of sympathetic neurons projecting to the gastrointestinal in the rats. Arch Histol Cytol 2001; 64: 281-294, doi: 10.1679/aohc.64.281.

50. Takeuchi K. Pathogenesis of NSAID-induced gastric damage: Importance of cyclooxygenase inhibition and gastric hypermotility. World J Gastroenterol 2012; 18: 2147-2160, doi: 10.3748/wjg.v18.i18.2147.

51. Souza MHLP, Troncon LEA, Cunha FQ, Oliveira RB. Decreased gastric tone and delayed gastric emptying precede neutrophil infiltration and mucosal lesion formation in indomethacin-induced gastric damage in rats. Braz J Med Biol Res 2003; 36:1383-1390, doi: 10.1590/S0100-879X 2003001000015

52. Santos CL, Medeiros BA, Palheta-Junior RC, Macedo GM, Nobre-e-Souza MA, Troncon LEA, et al. Cyclooxygenase-2 inhibition increases gastric tone and delays gastric emptying in rats. Neurogastroenterol Motil 2007; 19: 225-232, doi: 10.1111/j.1365-2982.2007.00913.x.

53. Sánchez S, Alarcón de la Lastra C, Ortiz P, Motilva V, Martín MJ. Gastrointestinal tolerability of metamizol, acetaminophen, and diclofenac in subchronic treatment in rats. Dig Dis Sci 2002; 47: 2791-2798, doi: 10.1023/A:1021077810548.

54. Sánnchez $S$, Martin MJ, Ortiz P, Motiva V, Herrérias JM, Alarcón de la Lastra A. Role of prostaglandins and nitric oxide in gastric damage induced by metamzol in rats. Inflamm Res 2002; 51: 385-392, doi: 10.1007/PL00000319.

55. Pierre SC, Schmidt R, Brenneis C, Michaelis M, Geisslinger $\mathrm{G}$, Scholich E. Inhibition of cyclooxygenases by dipyrone. Brit J Pharmacol 2007; 151: 494-503, doi: 10.1038/sj.bjp. 0707239.

56. Batu OS, Erol K. The effects of some nonsteroidal antiinflammatory drugs on experimental induced gastric ulcers in rats. Inflammopharmacology 2007; 15: 260-265, doi: 10. 1007/s10787-007-1605-1.

57. Yıldırım E, Sağıroğlu O, Kılıç FS, Erol K. Effects of nabumetone and dipyrone on experimentally induced gastric ulcers in rats. Inflammation 2013; 36: 476-481, doi: 10.1007/ s10753-012-9568-9.

58. Andrade S, Bartels DB, Lange R, Sandford L, Gurwitz J. Safety of metamisole: a systemic review of literature. J Clin Pharm Ther 2016; 41: 459-477, doi: 10.1111/jcpt.12422.

59. Bianchi Porro G, Ardizzone S, Petrillo M, Caruso I, Montrone F. Endoscopic assessment of the effect of dipyrone (metamizol) in comparison to paracetamol and placebo on the gastric and duodenal mucosa of healthy adult volunteers. Digestion 1996; 57: 186-190, doi: 10.1159/ 000201336.

60. Hunt RH, Camilleri M, Crowe SE, El-Omar EM, Fox JG, Kuipers EJ, et al. The stomach in health and disease. Gut 2015; 64: 1650-1668, doi: 10.1136/gutjnl-2014-307595.

61. Canfield SP, Price CA. A comparison of the effects of sympathomimetic agents on gastric acid secretion by the rat stomach in vivo and in vitro. J Physiol 1981; 316: 11-21, doi: 10.1113/jphysiol.1981.sp013768.

62. Kaan SK, Cho CH. A study of the antiulcer mechanisms of propranolol in rats. Inflamm Res 1996; 45: 370-375, doi: 10.1007/BF02252930.

63. Kaan SK, Cho $\mathrm{CH}$. Effects of selective $\beta$-adrenoceptor antagonists on gastric ulceration in the rats. J Pharm Pharmacol 1997; 49: 200-205, doi: 10.1111/j.2042-7158. 1997.tb06779.x.

64. Lindner E. [Experimental studies on action of a pyrazolone derivative on smooth-musculed organs]. Arzneimittelforschung 1956; 6: 124-127.

65. Alexander K, Khreis A, Traut G. [The combined effect of noramidopyrine-methanesulfonate with choline and acetylcholine]. Arzneimittelforschung 1963; 13: 493-497.

66. Schiantarelli $P$, Murmann $\mathrm{W}$, Magi S. Investigation of rociverine + dipyrone for antispasmodic and analgesic interactions. Arzneimittelforschung 1979; 29: 760-765.

67. Hertle L, Nawrath H. [Effect of Baralgin on isolated preparations of upper urinary tract in man]. Urol Int 1984; 39: 84-90, doi: 10.1159/000280951.

68. Forth W. Spasmolytic effects of pyrazolone drugs. Agents Actions Suppl 1986; 19: 169-175, doi: 10.1007/BF01966 202.

69. Ergün H, Frattarelli DAC, Aranda JV. Characterization of the role of physicochemical factors on the hydrolysis of dipyrone. J Pharm Biomed Anal 2004; 35: 479-487, doi: 10. 1016/j.jpba.2004.02.004.

70. Herbert MK, Weis R, Holzer P, Roewer N. Peristalsis in guinea pig small intestine in vitro is impaired by acetaminophen but not aspirin and dipyrone. Anesth Analg 2005; 100: 120-127, doi: 10.1213/01.ANE.0000139352.54676.18.

71. Donnerer J, Liebmann I. Effects of allyl Isothiocyanate, acetaminophen, and dipyrone in the guinea-pig ileum. Pharmacology 2017; 99: 79-83, doi: 10.1159/000452164.

72. Roelvink ME, Goosens L, Kalsbeek HC, Wensing T. Analgesic and spasmolytic effects of dipyrone, hyoscine-Nbutylbromide and a combination of the two ponies. Vet Rec 1991; 129: 378-380, doi: 10.1136/vr.129.17.378.

73. Adams SB, Lamar CH, Masty J. Motility of the distal portion of jejunum and pelvic flexure in ponies: Effects of six drugs. Am J Vet Res 1984; 45: 795-799.

74. Coelho JC, Senninger N, Runkel N, Herfarth C, Messmer K. Effect of analgesic drugs on the electromyographic activity of the gastrointestinal tract and sphincter of Oddi and on biliary pressure. Ann Surg 1986; 204: 53-58, doi: 10.1097/ 00000658-198607000-00007.

75. Toouli J. Sphincter of Oddi: Function, dysfunction, and its management. J Gastroent Hepatol 2009; 24: S57-S62, doi: 10.1111/j.1440-1746.2009.06072.x.

76. Schmieder G, Stankov G, Zerle G, Schinzel S, Brune K. Observer-blind study with metamizole versus tramadol and butylscopolamine in acute biliary colic pain. Arzneimittelforschung 1993; 43: 1216-1221. 
77. Basurto Oña X, Robes Perea L. [Anti-inflammatory drugs for biliary colics: systematic review and meta-analysis of randomized controlled trials]. Gastroenterol Hepatol 2008; 31: 1-7, doi: 10.1157/13114562.

78. Coli A, Conte D, Valle SD, Sciola V, Fraqueli M. Metaanalysis: nonsteroidal anti-inflammatory drugs in biliary colic. Aliment Pharmacol Ther 2012; 35: 1370-1378, doi: 10.1111/ j.1365-2036.2012.05115.x.

79. Brandstätter G, Schinzel S, Wurzer H. Influence of spasmolytic analgesics on motility of sphincter of Oddi. Dig Dis Sci 1996; 41: 1814-1818, doi: 10.1007/BF02088751.

80. Behar J. Physiology and pathophysiology of biliary tract: The gallbladder and sphincter of Oddi--A review. ISRN Physiology 2013; 2013: 837630, doi: 10.1155/2013/837630.

81. Kyanam KR, Baig K, Wilcox CM. Translational and clinical perspecitives on sphincter of Oddi function. Clin Exp Gastroenterol 2016; 9: 191-195.

82. Kyösola K. Sympatho-adrenergic neuronal control of the sphincter of Oddi of cat and the dog. Tohoku J Exp Med 1979; 127: 113-117, doi: 10.1620/tjem.127.113.

83. Balemba OB, Salter MJ, Mawe GM. Innervation of extrahepatic biliary tract. Anat Rec A Discov Mol Cell Evol Biol 2004; 280: 836-847, doi: 10.1002/ar.a.20089.

84. Alcón S, Morales S, Camello PJ, Salido GM, Miller SM, Pozo MJ. Relaxation of canine gallbladder to nerve stimulation involves adrenergic and non-adrenergic non-cholinergic mechanisms. Neurogastroenterol Mot 2001; 13: 555-566, doi: 10.1046/j.1365-2982.2001.00286.x.

85. Persson CG. Adrenoceptor functions in the cat choledochoduodenal junction studied in vitro. $\mathrm{Br} J$ Pharmacol 1971; 42: 447-461, doi: 10.1111/j.1476-5381.1971.tb07 130.x.

86. Liedberg G, Persson CG. Adrenoceptors in cat choledochoduodenal junction studied in situ. Br J Pharmacol 1970; 39: 619-626, doi: 10.1111/j.1476-5381.1970.tb10369.x.

87. Dahlstrand C, Dahlström A, Ahlman H. Adrenergic and VIPergic relaxatory mechanisms of the feline extrahepatic biliary tree. J Auton Nerv Syst 1989; 26: 97-106, doi: 10.1016/ 0165-1838(89)90157-4.

88. Baker JG. The selectivity of $\beta$-adrenoceptor antagonists at the human $\beta 1, \beta 2$ and $\beta 3$ adrenoceptors. Br J Pharmacol 2005; 144: 317-322, doi: 10.1038/sj.bjp.0706048.

89. Hernández-Delgadillo GP, López-Muñoz FJ, Salazar LA, Cruz SL. Morphine and dipyrone co-administration delays tolerance development and potentates antinociception. Eur J Pharmacol 2003; 469: 71-79, doi: 10.1016/S0014-2999 (03)01727-8.

90. Silva-Moreno A, López-Muñoz FJ, Cruz SL. D-propoxyphene and dipyrone co-administration produces greater antinociception fewer adverse effects than single treatments in rats. Eur J Pharmacol 2009; 607: 84-90, doi: 10.1016/ j.ejphar.2009.02.010. 